\title{
Disseminating evidence-based mental health practices
}

Why do people working in mental health fail to use evidence-based practices? A review of the literature suggests two main barriers to staff dissemination: 1) individual service providers lack the knowledge and skills to assimilate these practices and 2) organisational dynamics undermine staffs' ability to implement and maintain innovative approaches. Given these barriers, three strategies to foster dissemination may be useful: 1) packaging evidence-based practices so interventions are more user-friendly 2) educating providers about relevant knowledge and skills, and 3) addressing organisational dynamics that facilitate implementation. Research on dissemination is less developed than the clinical and services research that has led to evidence-based practices. There is a need for continued work on dissemination if evidence-based practices are to be used in the real-world.

There are many reasons why evidence-based strategies are not implemented in routine mental health care. These include administrative policies, funding priorities, community resources, advocate concerns, federal and state laws, local ordinances, local consumer interests and staffing. This article focuses on barriers to staff use of evidence-based treatments and strategies to reduce these barriers.

\section{Barriers to disseminating evidence-based practices}

There are two main sets of staff barriers to implementing evidence-based practices in mental health care:

1) Individual service providers may lack the skills to assimilate evidence-based practices into their regular approach to treatment. Moreover, work-related variables like job burnout undermine some staff's interest in new and innovative practices.

2) Many evidence-based practices require a team of service providers. Organisational barriers such as poor leadership, change-averse culture, insufficient collegial support and bureaucratic constraints may hinder a team's effort to implement evidence-based practices.

Providers who wish use an evidence-based approach need to have mastered three basic sets of competencies. They need to acquire attitudes that are the foundation of evidence-based practices. ${ }^{1}$ Most important among these is a change from seeing treatment as "working on" people to working with them. Providers also need a broad range of knowledge to assimilate evidencebased practices, including information about the impact of psychiatric disorders and about pharmacological and psychosocial interventions. Finally, providers need to master a series of skills including interpersonal support, instrumental support, goal setting and skills training. ${ }^{2}$

There are several reasons why individual staff may lack appropriate attitudes, knowledge and skills. Some never participate in formal (pre-service) training. Others receive training that is not germane to the principles of evidence-based practices. Some providers have the necessary knowledge and skills, but are unable to implement evidence-based guidelines because they are burned out. Research has found that staff with high levels of emotional exhaustion and depersonalisation are less likely to be aware of or implement innovative approaches. ${ }^{3}$ Moreover, they are less interested in learning new approaches. This is ironic because innovations may provide knowledge and skills that would help staff address work stressors and counteract burnout.

Staff burnout is also associated with diminished collegial support. Mental health providers who report a lack of cooperation and collaboration with peers are likely to be emotionally exhausted at work. ${ }^{4}$ Yet the success of many evidence-based practices requires coordinated efforts by a treatment team. A poorly coordinated team may be less able to follow a plan dynamically, that is, to change key parameters as the needs, resources and skills of the patient become more apparent. There are several reasons why collegial support fails to develop in a treatment team. Often, team members perceive a lack of control over decisions. Rather than representing what line-level providers believe to be key needs and concerns of their clients, staff may think service innovations, and their corresponding training initiatives, reflect the interests of administrators. ${ }^{5}$ Administrative priorities are often thought to reflect abstract political interests rather than the more pressing needs of the team and its clients. In addition, treatment teams suggest that their efforts are 'bogged down' by bureaucratic constraints, including tracking the implementation of evidence-based services. ${ }^{6}$ Leadership is another key variable for teamwork. Does the person responsible for supervising team members have the necessary skills to do so?

\section{Strategies that facilitate dissemination}

A variety of strategies may increase the dissemination of evidence-based practices. These include technology that makes evidence-based practices more user friendly, educational approaches that increase staff members' knowledge and skills and organisational strategies that enhance a team's ability to work collaboratively.

\section{MAKING TECHNOLOGY USER-FRIENDLY}

Sometimes evidence-based practices do not transfer well from academic to practice settings. The resources and policies that develop an innovative practice in a research environment may not parallel the demands of consumers, providers and administrators in the public mental health system. Treatment manuals and practice guidelines are a key tool for making evidencebased practices more accessible to line-level staff. Manuals outline the specific steps that therapists should use to guide patients. They serve as job aides to current and newly hired staff and are a hands-on resource that can be easily revised and updated.

Manuals serve several purposes. Micro-skills in treatment manuals may be learned quickly by line-level generalists. Hence, organisations need not hire specially trained and costly professionals to implement programmes. Treatment manuals often have high face-validity. This increases the likelihood that providers will understand the treatment's rationale and implement the technology. Treatment manuals typically have inbuilt fidelity systems. Practitioners can use these systems to ensure they implement the practice correctly. Outcome assessments to help staff assess whether consumer goals are being met may also be included. 


\section{EDUCATING STAFF}

Educational programmes fall into two categories: pre-service training (for students preparing for a career in mental health) and in-service training (for paraprofessionals and professionals to learn recently developed, evidence-based approaches to update their practices). In pre-service training, universities have identified a variety of competencies needed for contemporary positions. $^{7}$ There is evidence that students completing these curricula are adequately prepared for their jobs. ${ }^{8}$ A larger body of research has examined the impact of in-service training on the day-to-day practices of mental health workers. Like pre-service education, in-service programmes for line-level staff have focused on discrete skills. ${ }^{9}$ These programmes are often coupled with teaching staff how to use manuals. Providers who complete this kind of training may improve their attitudes about innovative practices,${ }^{10}$ learn skills ${ }^{11}$ and apply some of the skills in practice. ${ }^{12}$ Skills learned at in-service training are likely to be maintained over time if training is paired with ongoing, regular feedback. ${ }^{13}$

Although educational programmes are useful for disseminating evidence-based practices, they have two main limitations. First, many professionals and paraprofessionals do not participate or drop out before training is completed. ${ }^{14}$ As a result, a portion never receive training. Second, providers who learn new skills during in-service training may not continue to apply these skills.

\section{IMPROVING ORGANISATIONAL DYNAMICS}

There are several reasons why a team of mental health providers may not interact cohesively. A range of organisational strategies is therefore needed.

Improving team leadership: Transformational and transactional leadership styles are most effective for mental health teams. ${ }^{15}$ Leaders using transformational skills encourage staff to develop innovative ways to deal with work-related problems. Transformational leadership promotes inspiration, intellectual stimulation and individual consideration. Transactional leadership skills are more practical. They include goal-setting, feedback, self-monitoring and reinforcement strategies that help team members maintain effective programmes. Team leaders who receive training in transaction leadership increase supervisory feedback. Improved leadership has also been associated with consumer satisfaction and quality of life. ${ }^{16}$

Total quality management: Organisational psychologists have developed total quality management strategies for facilitating a team's ability to work together and implement effective interventions. ${ }^{17}$ Total quality management is a set of development strategies to improve the quality and productivity of the work environment from the 'bottom up' (from the level of the case manager, job coach and rehabilitation counselor charged with day-to-day implementation, for instance). Supervisors and administrators may be removed from day-to-day affairs. ${ }^{18}$ Development efforts are driven by data rather than opinion. ${ }^{19}$ Employees collect information to identify programme needs and client progress.

Organisational decision making efforts, like those supported by total quality management, often fall short when they are not specific to the needs of staff, or when they are implemented for only a short time. Studies of total quality management in evidence-based mental health practices are limited, though there has been some study of the charting and data gathering activities in service settings. ${ }^{20} 21$

Interactive staff training: Interactive staff training integrates education and total quality management approaches. ${ }^{22}$ It is dif- ferent from more traditional training in two ways. First, training focuses on the team in their practice setting. Teams can work together to learn new practices and form a viable plan for their agency. Second, interactive staff training encourages the development of user-friendly programmes.

\section{Summary}

Evidence-based practices offer significant promise for people with serious mental illness, although in practice this potential may not be realised. The effort and ingenuity put into crafting psychiatric services is also needed to disseminate and implement evidence-based approaches. Changing the mental health system, and the providers who staff it, requires interventions at several levels. We must work as hard at implementing evidencebased practices as we do at generating good quality research.

Note: A more detailed outline of the ideas presented here and further references are available in Strategies for disseminating evidence-based practices to staff who treat people with serious mental illness. Psychiatric Services 2001; 52: 1598-606.

PATRICK CORRIGAN

STANLEY MCCRACKEN BARBARA BLASER

Center for Psychiatric Rehabilitation

University of Chicago, USA

For correspondence:p-corrigan@uchicago.edu

1 Good T, Berenbaum H, Nisenson L. Residential caregiver attitudes toward seriously mentally ill persons. Psychiatry Interpersonal and Biological Processes 2000; 63: 23-33.

2 Jahr E. Current issues in staff training. Research in Developmental Disabilities 1998; 19: 73-87.

3 Donat D, McKeegan G. Behavioral knowledge and occupational stress among inpatient psychiatric caregivers. Psychiatric Rehabilitation Journal 1997; 21: 67-9.

4 Corrigan PW, Holmes EP, Luchins D et al. Staff burnout in psychiatric hospitals: a cross legged panel design. Journal of Organizational Behavior 1994; 15: 65-74

5 Milne D, Gorenski O, Westerman $\mathrm{C}$ et al. What does it take to transfer training? Psychiatric Rehabilitation Skills 2000; 4: 259-81.

6 Corrigan PW, Kwartarini WY, Pramana W. Barriers to the implication of behavior therapy. Behavior Modification 1992; 16: 132-44.

7 Backs AB, Giffort DW, McCracken SG et al. Public academic training partnership for paraprofessionals who provide psychiatric rehabilitation. nership for paraprofessionals who pro
Psychiatric Rehabilitation Skills, in press.

8 Gill KJ, Pratt CW, Barrett N. Preparing psychiatric rehabilitation specialists through undergraduate education. Community Mental Health Journal 1997; 33: $323-9$

9 Rogers ES, Cohen BF, Danley KS et al. Training mental health workers in psychiatric rehabilitation. Schizophrenia Bulletin 1986; 12: 709-19.

10 Berryman J, Evans IM, Kalbag A. The effects of training in nonaversive behavior management on the attitudes and understanding of direct care staff. Journal of Behavior Therapy and Experimental Psychiatry 1994; 25: 24150.

11 Rubel E, Sobell L, Miller W. Do continuing education workshops improve participants' skills: effects of a motivational interviewing workshop on
substance abuse counselors' skills and knowledge. AABT, The Behavior Therapist 2000; 23: 73-80.

12 Kavanagh DJ, Piatkowska O, Clark D et al. Application of cognitive behavioral interventions for schizophrenia in multidisciplinary teams: what can the matter be? Australian Psychologist 1993; 28: 181-8.

13 Liberman RP, Nuechterlein K, Wallace C. Social skills training and the nature of schizophrenia. Curran JP, Monti PM (eds). Social skills training: $a$ practical handbook for assessment and treatment. 1982: 5-56.

14 Liberman RP, Eckman T, Kuehnel T et al. Dissemination of new behavior therapy programs to community mental health programs. American Journal of Psychiatry 1982; 139: 224-6.

15 Avolio B, Bass B, Jung D. Re-examining the components of transformational and transactional leadership using the multifactor leadership questional and transactional leadership using the multifactor leadership ques-
tionnaire. Journal of Occupational and Organizational Psychiatry 1999; 72: tionnaire.

17 Sluyter G. Total quality management in behavioral health care. New Directions for Mental Health Services 1998; 79: 35-43.

18 Marks ML, Mirvis P, Hackett E et al. Employee participation in a quality circle program: impact on quality of work life, productivity, and absenteeism. Journal of Applied Psychology 1986; 71: 61-9.

19 Fauman M. Quality assurance monitoring. Manual of Psychiatric Quality Assurance 1992: 57-67.

20 Hunter ME, Love CC. Total quality management and the reduction of inpatient violence and costs in a forensic psychiatric hospital. Psychiatric Services 1996; 47: 751-4.

21 Sluyter GV, Mukherjee AK. Total Quality Management for Mental Health and Mental Retardation Services: A Paradigm for the "90s. Annandale: American Network of Community Options and Resources, 1993.

22 Corrigan PW, McCracken SG. An interactive approach to training teams and developing programs. New Directions For Mental Health Services 1998; 79: 3-12. 